\section{International Conference on Semiconductor and IC Technology To Be Held in China}

An International Conference on Semiconductor and Integrated Circuit Technology is planned for October 1986 in Beijing, China. The conference is being co-sponsored by the Chinese Institute of Electronics and by the Continuing Education in Engineering, University Extension of the University of California at Berkeley. The technical focus of this international forum will be a broad review of materials and processing issues associated with the fabrication of semiconductor and IC devices. The Beijing location will provide an important opportunity to establish contacts with a large number of Chinese scientists and technologists.

The conference committee includes: Zheng Wenhao (Chinese Institute of Electronics), Yu Zhongyu (Ministry of Electronics Industries, China), Wang Yang Yuan (Peking University), Takuo Sugano (Tokyo University), Michael Strathman (Charles Evans \& Associates), Nathan Cheung (University of California, Berkeley), and James Stimmell (National Semiconductor). Papers are expected to address the following topics: lithography, ion implantation, diffusion/ oxidation, Si materials, rapid thermal processing, thin-film deposition, amorphous Si, MOS technology, bipolar technology, IC circuit design, yield/reliability, etching, packaging, process characterization, materials characterization, clean-room technology, electronic-grade chemicals, high-purity water, toxic-materials handling, fab safety and maintenance, education and training, fab management and superconductor electronics.

The conference is scheduled for a sevenday period beginning the week of October 19,1986 . It will feature four days of talks and poster sessions. There will be several plenary sessions devoted to opportunities for cooperation and joint ventures in China. Tours of factories, research institutes, universities, and other sites in the Beijing area will emphasize computer, communication, and IC fabrication facilities. Opportunities for additional interaction will be provided at the factory sites and research laboratories.

Contact Continuing Education in Engineering, University Extension, University of California, 2223 Fulton Street, Berkeley, CA 94720 .

\title{
Vivienne Harwood Mattox Appointed Short Course Manager
}

Vivienne Harwood Maddox has recently ben appointed short course manager of the Materials Research Society Short Course Program to further the Society's goal in providing broader and more comprehensive educational courses. In making the announcement, MRS Vice President Gordon E. Pike remarked, "Vivienne's extensive experience in teaching and management of continuing education in high-technology areas will be extremely valuable to MRS's rapidly growing Short Course Program."

Mattox brings to MRS a wide variety of experience in scientific research, teaching, vacuum system design, marketing, and in the development of short course programs. She received a BSc with honors in physics from the University of Exeter, England in 1959. In the early 1960s, she conducted research on the compressive and tensile strength of coal at the Mining Research Establishment of the National Coal Board in England while teaching part-time as a lecturer in physics. From 1961-1964, she was a full-time lecturer in physics at the Bristol College of Science and Technology, where she developed and taught a laboratory course in vacuum science and technology for college students and representatives from industry.

She became assistant professor in the electrical engineering department of the University of Alberta, Canada in 1964, where she developed a teaching laboratory and graduate course in vacuum science and technology. While vacuum design group leader for TRIUMF (Tri-University Meson Facility) at the University of British Columbia from 1966-1969, she designed and supervised the construction of the vacuum system of the accelerator. Following

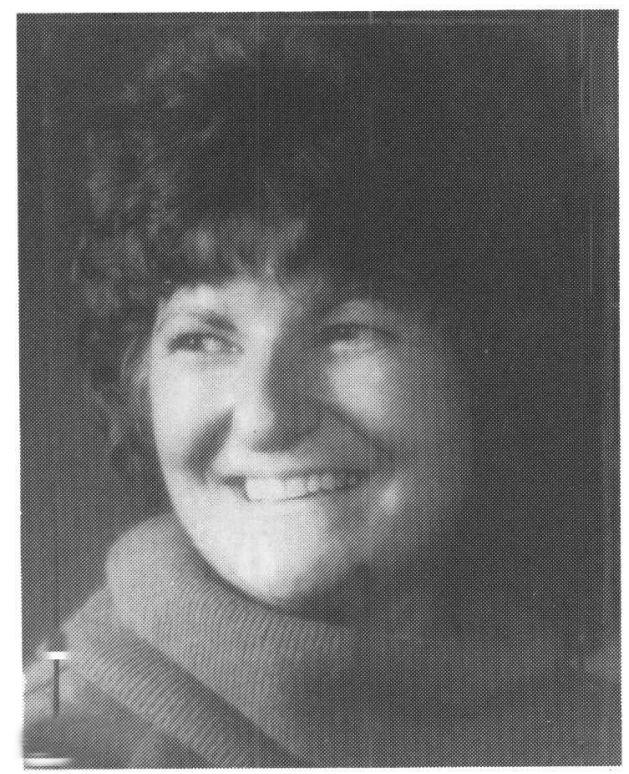

Vivienne Harwood Mattox

her move to Bethesda, Maryland in 1969, she started her own marketing business in the real estate field

From 1969-1984, Mattox devoted extensive time to the Education Committee of the American Vacuum Society and greatly expanded the educational services of the Society. She coordinated a book of laboratory experiments used for teaching vacuum technology and organized the first national AVS short course offering in 1970. As Education Committee Chairperson from 1974-1976, she supervised the production of the U. S. contribution of visual aids to the international project of IUVSTA, and initiated the production of Society monographs from short course notes.
She was the short course coordinator for the American Vacuum Society from 19771983, during which time she was responsible for the dramatic growth of the AVS short course program. After a reorganization of the program to cope with its growth, Mattox assumed the role of technical marketing chairperson until moving to Albuquerque in 1984. She served as an elected member of the AVS Board of Directors from 19801981, and has received several awards from the American Vacuum Society for her contributions to the development of its short course program.

\section{MRS SHORT COURSES} in conjunction with the Spring Meeting Palo Alto, California

Look for course details in the mail or contact MRS Headquarters at (412) 367-3003. 